International Journal of Pure and Applied Mathematics

Volume 101 No. $1 \quad 2015,43-53$

ISSN: 1311-8080 (printed version); ISSN: 1314-3395 (on-line version)

url: http://www.ijpam.eu

doi: http://dx.doi.org/10.12732/ijpam.v101i1.5

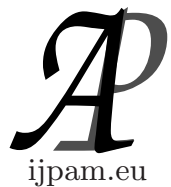

\title{
WEAKLY $T_{F}$ TYPE CONTRACTIVE MAPPINGS
}

\author{
Mehmet $\operatorname{Kir}^{1} \S$, Hukmi Kiziltunc ${ }^{2}$ \\ ${ }^{1,2}$ Department of Mathematics \\ Ataturk University \\ 25240, Erzurum, TURKEY
}

\begin{abstract}
In this paper, the concept of weakly $T_{F}$-contractive conditions are considered for the Banach, Kannan and Chatterjea fixed point theorems. It is shown that these mappings have a unique fixed point in a complete metric space.
\end{abstract}

AMS Subject Classification: $47 \mathrm{H} 10$

Key Words: fixed point, Chatterjea fixed point theorem,Kannan fixed point theorem, contraction mappings, $T_{F}$-contractive conditions

\section{Introduction and Preliminaries}

In 1922, Banach proved his famous theorem which ensures the existence and uniqueness of the fixed point.

A mapping $T: X \rightarrow X$, where $(X, d)$ is a metric space, is said to be a contraction if there exists $k \in[0,1)$ such that for all $x, y \in X$,

$$
d(T x, T y) \leq k d(x, y) .
$$

If the metric space $(X, d)$ is complete then the mapping satisfying (1.1) has a unique fixed point.

It is clear that the inequality (1.1) implies the continuity of $T$. A natural

Received: December 29, 2014

(C) 2015 Academic Publications, Ltd.

$\S_{\text {Correspondence author }}$ url: www.acadpubl.eu 
question is that whether one can find a contractive condition which will imply the existence of the fixed point but will not imply continuity of the mappping. Kannan [2] established the following result in which the question has been answered in the affirmative.

Theorem 1. [2] If a mapping $T: X \rightarrow X$ where $(X, d)$ is a complete metric space, satisfies the inequality

$$
d(T x, T y) \leq a[d(x, T x)+d(y, T y)]
$$

where $a \in\left[0, \frac{1}{2}\right)$ and $x, y \in X$, then $T$ has a unique fixed point.

A similar contractive condition has been introduced by Chatterjea [3] as following:

Theorem 2. [3] If a mapping $T: X \rightarrow X$ where $(X, d)$ is a complete metric space, satisfies the inequality

$$
d(T x, T y) \leq b[d(x, T y)+d(y, T x)]
$$

such that $b \in\left[0, \frac{1}{2}\right)$ and $x, y \in X$, then $T$ has a unique fixed point.

In 2010, Moradi and Beiranvand gave the following result [8]:

Theorem 3. ( $T_{F}$-Contraction Mapping Theorem $)$ Let $(X, d)$ be a complete metric space and $T, f: X \rightarrow X$ be self-mappings such that $T$ is one-to-one and graph closed (or subsequentially convergent and continuous ). Let $f$ satisfying the inequality

$$
F(d(T f x, T f y)) \leq \alpha F(d(T x, T y))
$$

where $\alpha \in[0,1)$ and $F:[0, \infty) \rightarrow[0, \infty)$ is nondecreasing continuous from the right and $F^{-1}(0)=\{0\}$. Then $f$ has a unique fixed point in the complete metric space $(X, d)$.

In this study our purpose is to introduce weakly $T_{F}$ contractive conditions for Banach fixed point theorem, Kannan fixed point theorem and Chatterjea fixed point theorem.

Definition 1. [4] Let $(X, d)$ be a metric space. A mapping $T: X \rightarrow X$ is said to be sequentially convergent if we have, for every sequence $\left\{y_{n}\right\}$, if 
$\left\{T y_{n}\right\}$ converges then $\left\{y_{n}\right\}$ is also convergent. $T$ is said to be subsequentially convergent if we have, for every sequence $\left\{y_{n}\right\}$, if $\left\{T y_{n}\right\}$ converges then $\left\{y_{n}\right\}$ has a convergent subsequence.

\section{Main Results}

For the simplicity, we will use the following symbols.

1) We donote by $\digamma$ the set of all functions $F:[0, \infty) \rightarrow[0, \infty)$ which are continuous, monotone nondecreasing and $F(t)=0$ if and only if $t=0$.

2) We denote by $\Psi$ the set of all functions $\psi:[0, \infty) \rightarrow[0, \infty)$ is a continuous function such that $\psi(t)=0$ if and only if $t=0$.

3) Also, we denote by $S S C(X)$ the set of all mappings $T: X \rightarrow X$ such that $T$ is one-to-one, continuous and subsequentially convergent, by $S C(X)$ the set of all mappings $T: X \rightarrow X$ such that $T$ is one-to-one, continuous and sequentially convergent.

Theorem 4. ( Weakly $T_{F}$ Contractive Mapping Theorem ) Let $(X, d)$ be a complete metric space and $f: X \rightarrow X$ be a mapping. Let $T \in S S C$ and $f$ satisfy the inequality

$$
F(d(T f x, T f y)) \leq F(d(T x, T y))-\psi(d(T x, T y))
$$

where $F \in \digamma, \psi \in \Psi$. Then $f$ has a unique fixed point in $X$. Also, if $T$ is sequentially convergent then, for every $x_{0} \in X$ the sequence of iterates $\left\{f^{n} x_{0}\right\}$ converges to the fixed point.

Proof. Let $x_{0}$ be an arbitrary point in $X$. We define the sequence $\left\{x_{n}\right\}$ by $x_{n+1}=f x_{n}=f^{n+1} x_{0} \quad n=1,2, \cdots$. Using (2.1), we have

$$
\begin{aligned}
F\left(d\left(T x_{n}, T x_{n+1}\right)\right) & =F\left(d\left(T f x_{n-1}, T f x_{n}\right)\right) \\
& \leq F\left(d\left(T x_{n-1}, T x_{n}\right)\right)-\psi\left(T x_{n-1}, T x_{n}\right) \\
& \leq F\left(d\left(T x_{n-1}, T x_{n}\right)\right) .
\end{aligned}
$$

This implies that

$$
d\left(T x_{n}, T x_{n+1}\right) \leq d\left(T x_{n-1}, T x_{n}\right) .
$$

It is clear $\left\{d\left(T x_{n}, T x_{n+1}\right)\right\}$ is a monotone decreasing sequence, and consequently there exists an $r \geq 0$ such that

$$
d\left(T x_{n}, T x_{n+1}\right) \rightarrow r \text { as } n \rightarrow \infty .
$$


Letting $n \rightarrow \infty$ in (2.2), we obtain that $F(r) \leq F(r)-\psi(r)$. This case implies that $r=0$.

Now,we will prove that $\left\{T x_{n}\right\}$ is a Cauchy sequence. Suppose that $\left\{T x_{n}\right\}$ is not a Cahucy sequence. Then there exists an $\epsilon>0$ and there exist subsequences $\left\{T x_{m(k)}\right\},\left\{T x_{n(k)}\right\}$ of $\left\{T x_{n}\right\}$ with $n(k)>m(k)>k$ such that

$$
d\left(T x_{m(k)}, T x_{n(k)}\right) \geq \epsilon .
$$

Further, corresponding to $m(k)$, we can choose $n(k)$ in such a way that it is the smallest integer with $n(k)>m(k)$ and

$$
d\left(T x_{m(k)}, T x_{n(k)-1}\right)<\epsilon .
$$

Also, using (2.4) we have

$$
\begin{aligned}
\epsilon & \leq d\left(T x_{m(k)}, T x_{n(k)}\right) \\
& \leq d\left(T x_{m(k)}, T x_{n(k)-1}\right)+d\left(T x_{n(k)}, T x_{n(k)-1}\right) \\
& <\epsilon+d\left(T x_{n(k)}, T x_{n(k)-1}\right) .
\end{aligned}
$$

Letting $k \rightarrow \infty$ in (2.6), we have

$$
\lim _{k \rightarrow \infty} d\left(T x_{m(k)}, T x_{n(k)}\right)=\epsilon
$$

Again, we have

$$
\begin{aligned}
d\left(T x_{n(k)}, T x_{m(k)}\right) \leq & d\left(T x_{n(k)}, T x_{n(k)-1}\right)+d\left(T x_{n(k)-1}, T x_{m(k)-1}\right)(2.8 \\
& +d\left(T x_{m(k)-1}, T x_{m(k)}\right) \\
\leq \quad & d\left(T x_{n(k)}, T x_{n(k)-1}\right) \\
+ & {\left[d\left(T x_{n(k)-1}, T x_{n(k)}\right)+d\left(T x_{n(k)}, T x_{m(k)}\right)\right.} \\
& \left.+d\left(T x_{m(k)}, T x_{m(k)-1}\right)\right] \\
& +d\left(T x_{m(k)-1}, T x_{m(k)}\right)
\end{aligned}
$$

letting $k \rightarrow \infty$ in (2.8) and (2.9), we have

$$
\epsilon \leq \lim _{k \rightarrow \infty} d\left(T x_{n(k)-1}, T x_{m(k)-1}\right) \leq \epsilon .
$$

This implies that

$$
\lim _{k \rightarrow \infty} d\left(T x_{n(k)-1}, T x_{m(k)-1}\right)=\epsilon .
$$

Substituting (2.4) in (2.1) 


$$
\begin{aligned}
F(\epsilon) & \leq F\left(d\left(T x_{m(k)}, T x_{n(k)}\right)\right) \\
& =F\left(d\left(T f x_{m(k)-1}, T f x_{n(k)-1}\right)\right) \\
& \leq F\left(d\left(T x_{m(k)-1}, T x_{n(k)-1}\right)\right)-\psi\left(d\left(T x_{m(k)-1}, T x_{n(k)-1}\right)\right)
\end{aligned}
$$

use the (2.7), (2.11) in both (2.12) and (2.13)

$$
F(\epsilon) \leq F(\epsilon)-\psi(\epsilon) .
$$

This implies that $\epsilon=0$. But this case is a contradiction. Thus $\left\{T x_{n}\right\}$ is a Cauchy sequence in the complete metric space $X$. Hence, there is $v \in X$ such that

$$
\lim _{n \rightarrow \infty} T x_{n}=v .
$$

Since $T$ is subsequentially convergent, $\left\{x_{n}\right\}$ has a convergent subsequence. Thus there is an $u \in X$ such that

$$
\lim _{k \rightarrow \infty} x_{n(k)}=u .
$$

Since $T$ is continous and $x_{n(k)} \rightarrow u$, we have

$$
\lim _{n \rightarrow \infty} T x_{n(k)}=T u .
$$

Since $\left\{T x_{n(k)}\right\}$ is a subsequence of $\left\{T x_{n}\right\}$, so that $T u=v$. Now, we will show that $u \in X$ is a fixed point of $f$.

$$
\begin{aligned}
F\left(d\left(T x_{n(k)}, T f u\right)\right) & =F\left(d\left(T f x_{n(k)-1}, T f u\right)\right) \\
& \leq F\left(d\left(T x_{n(k)-1}, T u\right)-\psi\left(d\left(T x_{n(k)-1}, T u\right)\right)(\right.
\end{aligned}
$$

Letting $k \rightarrow \infty$ in (2.18) and using the (2.16), (2.17) we have

$$
F(d(T u, T f u)) \leq F(0)-\psi(0)
$$

this implies that $F(d(T u, T f u))=0$. As $T$ is one-to-one, then $f u=u$. To prove the uniqueness of the fixed point, assume that $u^{\prime} \in X$ is an other fixed points of $f$. Thus we have $f u^{\prime}=u^{\prime}$ and

$$
\begin{aligned}
F\left(d\left(T u, T u^{\prime}\right)\right) & =F\left(d\left(T f u, T f u^{\prime}\right)\right) \\
& \leq F\left(d\left(T u, T u^{\prime}\right)\right)-\psi\left(d\left(T u, T u^{\prime}\right)\right) .
\end{aligned}
$$


Inequality (2.20) is a contradiction unless $\psi\left(d\left(T u, T u^{\prime}\right)\right)=0$. This implies that $T u=T u^{\prime}$. Since $T$ is one-to-one $u=u^{\prime}$, that is, the fixed point is unique.

Also, if $T$ is sequentially convergent, by replacing $\{n\}$ with $\{n(k)\}$ we obtain that

$$
\lim _{n \rightarrow \infty} x_{n}=u \text {. }
$$

This implies that $\left\{x_{n}\right\}$ converges to the fixed point of $f$.

Remark 1. In Theorem 4, if we take $\psi(t)=k F(t)$ where $t \in[0, \infty)$ and $k \in(0,1]$, we obtain the above result that given by Moradi and Beiranvand [8].

If we take $T x=x$, we obtain the following result given by Dutta and Choudhury [6].

Corollary 1. Let $(X, d)$ be a complete metric space and let $f: X \rightarrow X$ be a self-mapping satisfying the inequality

$$
\psi(d(f x, f y)) \leq \psi(d(x, y))-\phi(d(x, y))
$$

where $\psi, \phi:[0, \infty) \rightarrow[0, \infty)$ are both continuous and monotone nondecreasing functions with $\psi(t)=0=\phi(t)$ if and only if $t=0$. Then $f$ has a unique fixed point.

If we take $T x=x$ and $F(s)=\int_{0}^{s} \varphi(t) d t$ with $\psi(t)=k F(t)$ where $t \in[0, \infty)$ and $k \in(0,1)$, then we obtain the following result given by Branciari [11].

Corollary 2. Let $(X, d)$ be a complete metric spaces and let $f: X \rightarrow X$ be a mapping such that for each $x, y \in X$ and $c \in(0,1)$,

$$
\int_{0}^{d(f x, f y)} \varphi(t) d t \leq c \int_{0}^{d(x, y)} \varphi(t) d t
$$

where $\varphi:[0, \infty) \rightarrow[0, \infty)$ is a Lebesgue-integrable mapping which summeble (i.e., with finite integral ) on each compact subset of $[0, \infty)$, nonnegative, and such that for each $\epsilon>0, \int_{0}^{\epsilon} \varphi(t) d t>0$; then $f$ has a unique fixed point $a \in X$ such that for each $x \in X, \lim _{n \rightarrow \infty} f^{n} x=a$. 
Theorem 5. ( Weakly $T_{F}$ Kannan Contractive Mapping Theorem ) Let $(X, d)$ be a complete metric space and $f: X \rightarrow X$ be mapping. Let $T \in S S C$ and $f$ satisfies the inequality

$$
\begin{aligned}
F(d(T f x, T f y)) \leq F\left(\frac{1}{2}[d(T x, T f x))\right. & +d(T y, T f y)]) \\
& -\psi(d(T x, T f x), d(T y, T f y))
\end{aligned}
$$

where $F \in \digamma, \psi \in \Psi$. Then $f$ has a unique fixed point. Also, if $T$ is sequentially convergent then for $x_{0} \in X$ the sequence of iterates $\left\{f^{n} x_{0}\right\}$ converges to this fixed point.

Proof. Let $x_{0} \in X$ and $\left\{x_{n}\right\}$ be a sequence in $X$ defined by $x_{n+1}=f x_{n}$, $n=1,2, \cdots$. Using the $(2.21)$, we have

$$
\begin{aligned}
F\left(d\left(T x_{n}, T x_{n+1}\right)\right)= & F\left(d\left(T f x_{n-1}, T f x_{n}\right)\right) \\
\leq & F\left(\frac{\left.d\left(T x_{n-1}, T f x_{n-1}\right)\right)+d\left(T x_{n}, T f x_{n}\right)}{2}\right) \\
& -\psi\left(d\left(T x_{n-1}, T f x_{n-1}\right), d\left(T x_{n}, T f x_{n}\right)\right) \\
= & F\left(\frac{d\left(T x_{n-1}, T x_{n}\right)+d\left(T x_{n}, T x_{n+1}\right)}{2}\right) \\
& -\psi\left(d\left(T x_{n-1}, T x_{n}\right)+d\left(T x_{n}, T x_{n+1}\right)\right) \\
\leq & F\left(\frac{d\left(T x_{n-1}, T x_{n}\right)+d\left(T x_{n}, T x_{n+1}\right)}{2}\right) .
\end{aligned}
$$

Note that $F$ is nondecreasing continuous, then we have $d\left(T x_{n}, T x_{n+1}\right) \leq$ $d\left(T x_{n-1}, T x_{n}\right)$. As the sequence $\left\{d\left(T x_{n}, T x_{n+1}\right)\right\}$ is a monotone decreasing sequence of non-negative real numbers, thus

$$
\lim _{n \rightarrow \infty} d\left(T x_{n}, T x_{n+1}\right)=0 .
$$

By following the similar method in the proof of the Theorem 4, we obtain that $\left\{T x_{n}\right\}$ is a Cauchy sequence in the complete metric space $(X, d)$. Therefore there is an $u \in X$ such that $x_{n} \rightarrow u$ and $T x_{n} \rightarrow v($ as $n \rightarrow \infty)$. Also, from the (2.21), we have

$$
\begin{aligned}
F\left(d\left(T x_{n+1}, T f u\right)\right) \leq F\left(\frac{d\left(T x_{n}, T f x_{n}\right)+d(T u, T f u)}{2}\right) \\
-\psi\left(d\left(T x_{n}, T f x_{n}\right), d(T u, T f u)\right)
\end{aligned}
$$

letting $n \rightarrow \infty$ in $(2.26)$, we have $\psi\left(d\left(T x_{n}, T f x_{n}\right), d(T u, T f u)\right) \leq 0$. Thus we get $u \in X$ is a fixed point of $f$. It is easy to see uniqness of the fixed point. 
If we take $F s=s$, then we obtain the following result, given by Moradi and Davood [7].

Corollary 3. Let $(X, d)$ be a complete metric space and T, $S: X \rightarrow X$ be mappings such that $T$ is continuous, one to one and subsequentially convergent. If $\mu \in\left[0, \frac{1}{2}\right)$ and $x, y \in X$,

$$
d(T S x, T S y) \leq \mu[d(T x, T S y)+d(T y, T S x)]
$$

then, $S$ has a unique fixed point. Also, if $T$ is sequentially convergent then for every $x_{0} \in X$ the sequence of iterates $\left\{S^{n} x_{0}\right\}$ converges to the fixed point.t.

Theorem 6. (Weakly $T_{F}$ Chatterjea Contractive Mapping Theorem ) Let $(X, d)$ be a complete metric space and $f: X \rightarrow X$ be a mapping. Let $T \in S S C$ and $f$ satisfies the inequality

$$
\begin{aligned}
F(d(T f x, T f y)) \leq F\left(\frac{1}{2}[d(T x, T f y))\right. & +d(T y, T f x)]) \\
& -\psi(d(T x, T f y), d(T y, T f x))
\end{aligned}
$$

where $F \in \digamma, \psi \in \Psi$. Then $f$ has a unique fixed point. Also if $T$ is sequentially convergent then for every $x_{0} \in X$ the sequence of iterates $\left\{f^{n} x_{0}\right\}$ converges to this fixed point.

Proof. Let $x_{0} \in X$ and $\left\{x_{n}\right\}$ be a sequence in $X$ defined by $x_{n+1}=f x_{n}$, such that $n=1,2, \cdots$. From the $(2.27)$, we have

$$
\begin{aligned}
F\left(d\left(T x_{n}, T x_{n+1}\right)\right)= & F\left(d\left(T f x_{n-1}, T f x_{n}\right)\right) \\
\leq & F\left(\frac{1}{2} d\left(T x_{n-1}, T x_{n+1}\right)\right) \\
& -\psi\left(d\left(T x_{n-1}, T x_{n+1}\right), 0\right) \\
\leq & F\left(\frac{d\left(T x_{n-1}, T x_{n}\right)+d\left(T x_{n}, T x_{n+1}\right)}{2}\right) .
\end{aligned}
$$

Since $F$ nondecreasing, we obtain that $d\left(T x_{n}, T x_{n+1}\right) \leq d\left(T x_{n-1}, T x_{n}\right)$. It is clear that $\left\{d\left(T x_{n}, T x_{n+1}\right)\right\}$ is a monotone decreasing sequence of non-negative real numbers. Hence there is an $r \in \mathbb{R}$ such that

$$
\lim _{n \rightarrow \infty} d\left(T x_{n}, T x_{n+1}\right)=r .
$$

From the (2.28), we have

$$
F\left(d\left(T x_{n}, T x_{n+1}\right)\right)=F\left(d\left(T f x_{n-1}, T f x_{n}\right)\right)
$$




$$
\begin{aligned}
& \leq F\left(\frac{1}{2}\left[d\left(T x_{n-1}, T f x_{n}\right)+d\left(T x_{n}, T f x_{n-1}\right)\right]\right) \\
& =F\left(\frac{1}{2}\left[d\left(T x_{n-1}, T x_{n+1}\right)\right]\right) \\
& \leq F\left(\frac{1}{2}\left[d\left(T x_{n-1}, T x_{n}\right)+d\left(T x_{n}, T x_{n+1}\right)\right]\right) .
\end{aligned}
$$

Letting $n \rightarrow \infty$ respectively, in (2.32), (2.33), (2.34) we obtain

$$
\lim _{n \rightarrow \infty} F\left(\frac{1}{2}\left[d\left(T x_{n-1}, T x_{n+1}\right)\right]\right)=F(r)
$$

Also, letting $n \rightarrow \infty$ in the $(2.28)$ we obtain that $\psi(r, 0)=0$. This implies that $r=0$.

Following the similar process in the proof of the Theorem 4, we obtain that $\left\{T x_{n}\right\}$ is a Cauchy sequence in the complete metric space $(X, d)$ and there is an $u \in X$ such that $x_{n} \rightarrow u$ and $T x_{n} \rightarrow v($ as $n \rightarrow \infty)$.

Also, from the 2.27 , we have

$$
\begin{aligned}
F\left(d\left(T x_{n+1}, T f u\right)\right)= & F\left(d\left(T f x_{n}, T f u\right)\right) \\
\leq & F\left(\frac{1}{2}\left[d\left(T x_{n}, T f u\right)+d\left(T u, T f x_{n}\right)\right]\right)- \\
& \psi\left(d\left(T x_{n}, T f u\right), d\left(T u, T f x_{n}\right)\right)
\end{aligned}
$$

letting $k \rightarrow \infty$ in 2.36, it follows that $\psi(d(T u, T f u), d(T u, T f u)) \leq 0$. This implies that $T u=T f u$. Note that $T$ is one-to-one so $f u=u$. Also, it is easy to see uniqness of the fixed point.

If we take $T x=x$ and $F x=x$ then, we obtain the following result given by Choudhury [2].

Corollary 4. Let $(X, d)$ be a complete metric space and $f: X \rightarrow X$ be a mapping such that for each $x, y \in X$,

$$
d(f x, f y) \leq \frac{1}{2}[d(x, f y)+d(y, f x)]-\psi(d(x, f y), d(y, f x))
$$

where $\psi:[0, \infty) \times[0, \infty) \rightarrow[0, \infty)$ is a continuous function such that $\psi(x, y)=0$ if and only if $x=y=0$. Then $f$ has a unique fixed point. 


\section{Acknowledgments}

The authors would like to thank Professor B.E. Rhoades for his constructive comments and suggestions on the pre-version of this paper.

\section{References}

[1] S. Banach, Sur les operations dans les ensembles abstraits et leur application aux equations integerales, Fundamenta Mathematicae, 3 (1922), 133181.

[2] R. Kannan, Some results on fixed points, Bull. Calcutta Math. Soc., 60 (1968), 71-76.

[3] S. Chatterjea, Fixed point theorems, C.R. Acad. Bulgare Sci., 25 (1972), 727-730.

[4] B.E. Rhoades, Some theorems on weakly contractive maps, Nonlinear Analysis: Theory, Methods and Applications, 47, No. 4 (2001), 2683-2693.

[5] B.S. Choudhury, Unique fixed point theorem for weakly $c$-contractive mappings, Kathmandu Univ. J. Sci. Eng. and Tech., 5, No. 1 (2009), 6-13.

[6] P.N. Dutta, B.S. Choudhury, A generalization of contraction principle in metric spces, Fixed Point Theory Appl. (2008), Article ID 406368.

[7] S. Moradi, A. Davood, New extension of Kannan fixed point theorem on complete metric and generalized metric spaces, Int. Journal of Math. Analysis, 5, No. 47 (2011), 2313-1320.

[8] S. Moradi, A. Beiranvand, Fixed point of $T_{F}$-contractive single-valued mappings, Iranian Journal of Mathematical Sciences and Informatics, $\mathbf{5}$ (2010), 25-32.

[9] E. Karapinar, Fixed point theory for cyclic weaker $\phi$-contraction, Appl. Math. Lett., 24, No. 6 (2011), 882-825.

[10] M. Kir, H. Kiziltunc, $T_{F}$ type contractive conditions for Kannan and Chatterjea fixed point theorems, Advances in Fixed Point Theory, 4, No. 1 (2014), 140-148. 
[11] A. Branciari, A fixed point theorem for mapping satisfying a general contractive condition of integral type, Int. J.M. and M. Sciences, 29, No. 9 (2002), 531-536. 
